\title{
Novel regenerative peptide TP508 mitigates radiation-induced gastrointestinal damage by activating stem cells and preserving crypt integrity
}

\author{
Carla Kantara', Stephanie M Moya ${ }^{1}$, Courtney W Houchen², Shahid Umar ${ }^{3}$, Robert L Ullrich ${ }^{4}$, Pomila Singh ${ }^{5}$ and \\ Darrell H Carney ${ }^{1,6}$
}

In recent years, increasing threats of radiation exposure and nuclear disasters have become a significant concern for the United States and countries worldwide. Exposure to high doses of radiation triggers a number of potentially lethal effects. Among the most severe is the gastrointestinal $(\mathrm{Gl})$ toxicity syndrome caused by the destruction of the intestinal barrier, resulting in bacterial translocation, systemic bacteremia, sepsis, and death. The lack of effective radioprotective agents capable of mitigating radiation-induced damage has prompted a search for novel countermeasures that can mitigate the effects of radiation post exposure, accelerate tissue repair in radiation-exposed individuals, and prevent mortality. We report that a single injection of regenerative peptide TP508 (rusalatide acetate, Chrysalin) $24 \mathrm{~h}$ after lethal radiation exposure $\left(9 \mathrm{~Gy}, \mathrm{LD}_{100 / 15}\right)$ appears to significantly increase survival and delay mortality by mitigating radiation-induced intestinal and colonic toxicity. TP508 treatment post exposure prevents the disintegration of Gl crypts, stimulates the expression of adherens junction protein E-cadherin, activates crypt cell proliferation, and decreases apoptosis. TP508 postexposure treatment also upregulates the expression of DCLK1 and LGR5 markers of stem cells that have been shown to be responsible for maintaining and regenerating intestinal crypts. Thus, TP508 appears to mitigate the effects of Gl toxicity by activating radioresistant stem cells and increasing the stemness potential of crypts to maintain and restore intestinal integrity. These results suggest that TP508 may be an effective emergency nuclear countermeasure that could be delivered within $24 \mathrm{~h}$ post exposure to increase survival and delay mortality, giving victims time to reach clinical sites for advanced medical treatment.

Laboratory Investigation (2015) 95, 1222-1233; doi:10.1038/labinvest.2015.103; published online 17 August 2015

The threat of a nuclear incident, with the potential to kill or injure thousands of people, has increased national and international recognition of the need for medicinal countermeasures that can prevent radiation-induced tissue damage and keep people alive, even if administered a day or more after nuclear exposure. ${ }^{1,2}$ Exposure to high doses of total body radiation ( $\geq 9 \mathrm{~Gy}$ ) triggers an acute gastrointestinal radiation toxicity syndrome (GI toxicity) that often results in death, regardless of intervention with advanced therapeutics or bone marrow transplants. ${ }^{3,4}$ The high mortality associated with GI toxicity is believed to be caused by the radiation-induced damage to the intestinal and colonic mucosa leading to reduced fluid absorption, electrolyte imbalance, barrier function loss, bacterial translocation, systemic bacterial infection, sepsis, and organ failure ${ }^{5-8}$ This sequence in the GI system is initiated by radiation-induced damage to stem cells that must continually proliferate to maintain crypt integrity and regeneration., ${ }^{9,10}$ Crypt cells in both the small intestine and colon are susceptible to radiation damage and serve as an indicator of potential survival following total body radiation. ${ }^{11}$ Hence, it is crucial to develop novel therapeutic drugs capable of preventing damage to GI crypt stem cells in order to increase survival.

To date, only a few mitigating or radioprotective agents have been approved by the FDA. ${ }^{12,13}$ Most of these are only effective in treating the hematopoietic syndrome triggered by

${ }^{1}$ Department of Biochemistry and Molecular Biology, University of Texas Medical Branch, Galveston, TX, USA; ${ }^{2}$ Department of Medicine, University of Oklahoma Health Sciences Center, Oklahoma City, OK, USA; ${ }^{3}$ Department of Molecular and Integrative Physiology, University of Kansas Medical Center, Kansas City, KS, USA; ${ }^{4}$ Department of Radiation Oncology, University of Texas Medical Branch, Galveston, TX, USA; 5 Department of Neuroscience and Cell Biology, University of Texas Medical Branch, Galveston, TX, USA and ${ }^{6}$ Chrysalis BioTherapeutics, Inc., Galveston, TX, USA

Correspondence: Dr DH Carney, PhD or Dr P Singh, PhD, Department of Biochemistry and Molecular Biology, The University of Texas Medical Branch, 6.136 Medical Research Building, 301 University Blvd, Route 1079, Galveston, TX 77555-1079, USA.

E-mail: dcarney@utmb.edu or posingh@utmb.edu

Received 25 March 2015; revised 22 May 2015; accepted 7 July 2015 

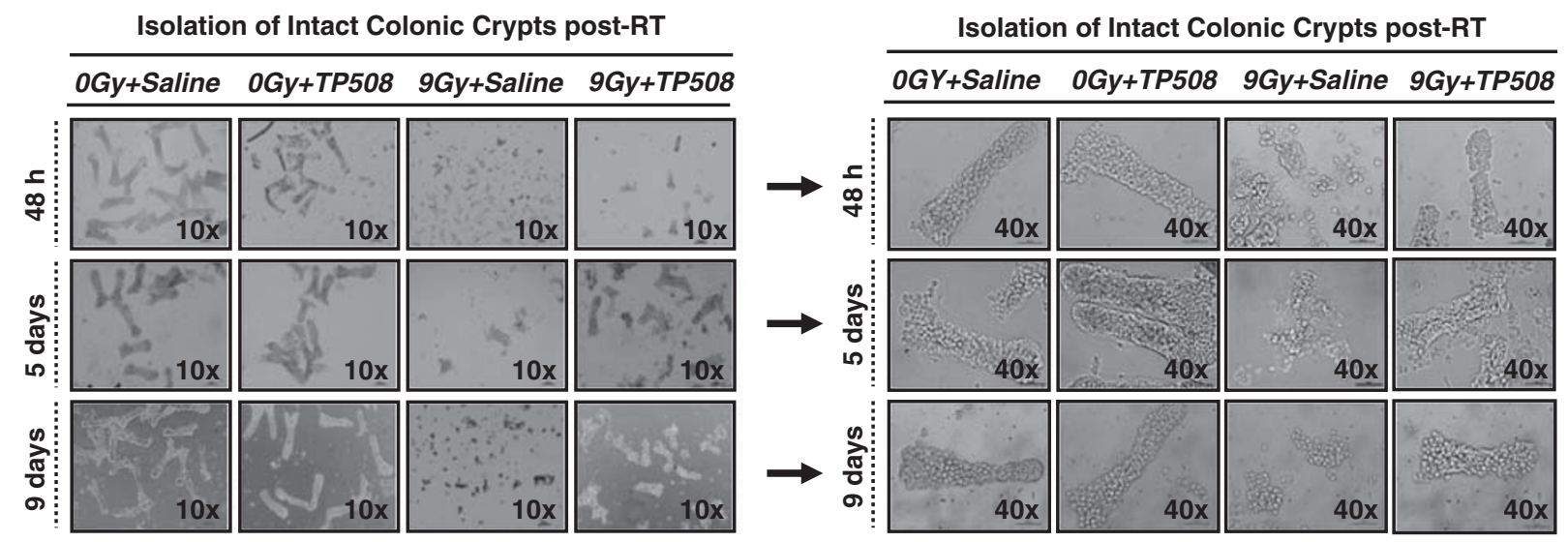

b H\&E Staining of Colonic Crypts post-RT
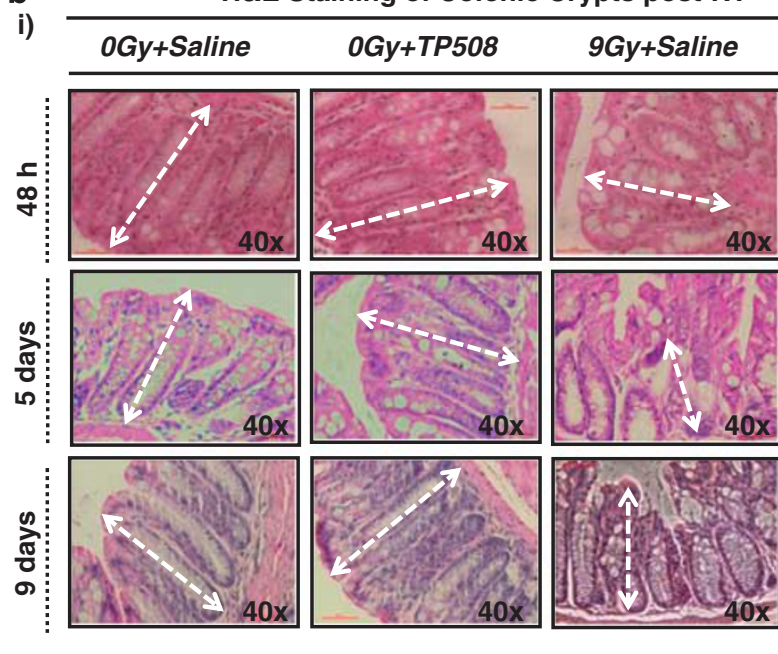

$9 G y+T P 508$
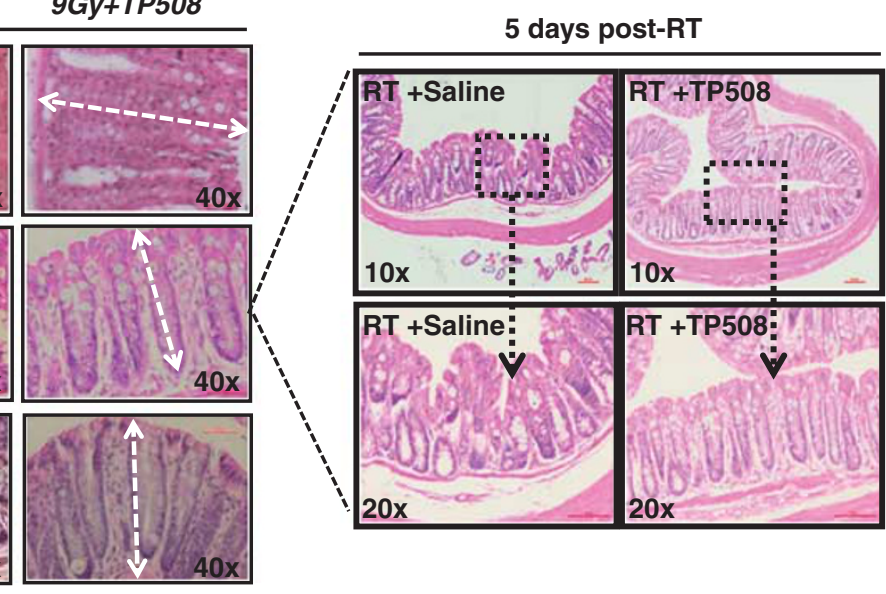

ii)
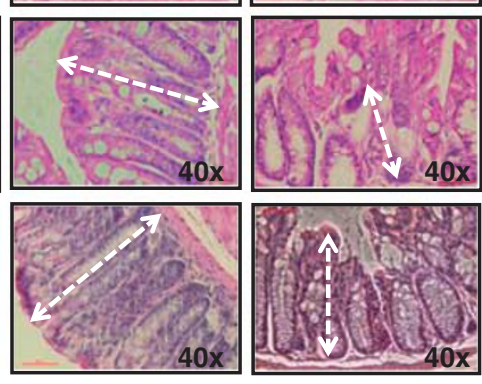

48h

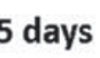

\section{$\square 9$ days}

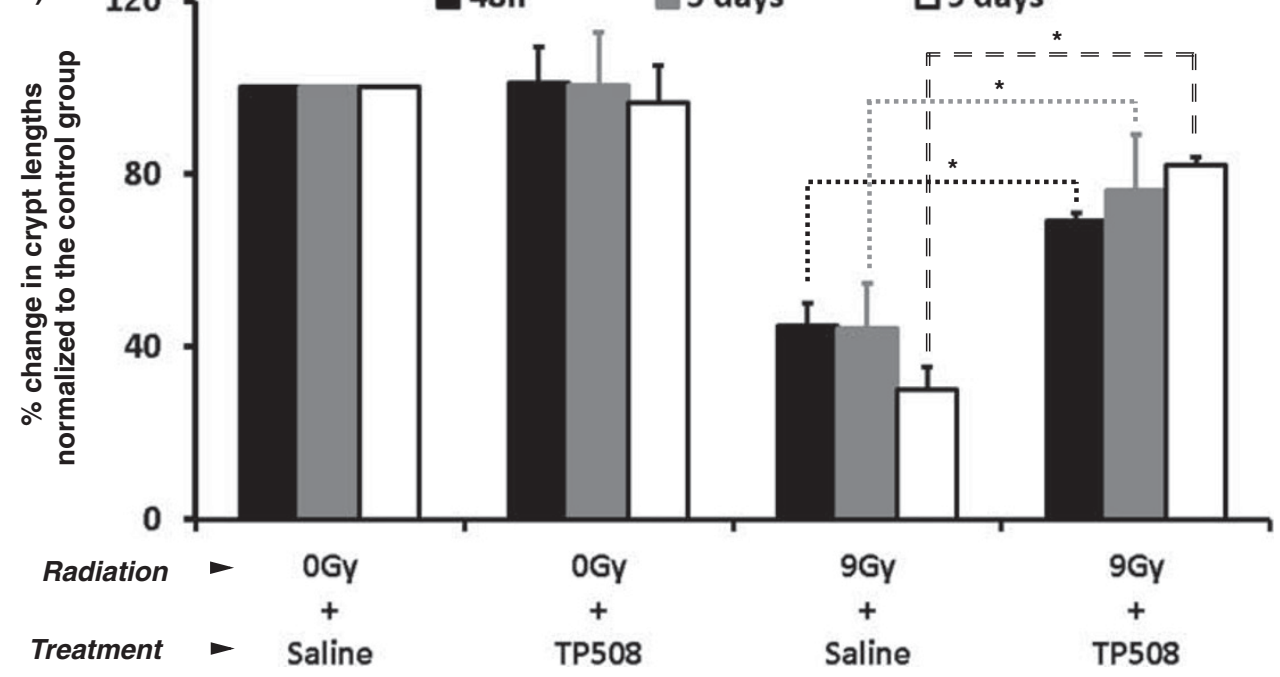

Figure 1 Effects of TP508 on gastrointestinal colonic crypts integrity post-radiation exposure. (a) Representative images taken at $\times 10$ and $\times 40$ magnifications of intact colonic crypts harvested at $48 \mathrm{~h}, 5$ days and 9 days post-RT from mice treated with either Saline or TP508, $24 \mathrm{~h}$ post radiation ( 0 or $9 \mathrm{~Gy}$ ). (bi-ii) Representative H\&E staining of colonic crypts sections harvested at $48 \mathrm{~h}$, day 5 and 9 days post-RT, from mice treated with the indicated treatments. Inset illustrating H\&E images from colonic crypts isolated 5 days post-RT is shown in the right-hand panel. White arrows depict change in crypt lengths. (bii) Bar graphs showing the percent change in crypt lengths normalized to the control (0 Gy+Saline) group, isolated $48 \mathrm{~h}$, 5 days and 9 days post-RT, respectively. Data $=$ mean \pm s.e.m. from 6 mice/group $/ 3$ experiments. ${ }^{*} P<0.05$ vs 9 Gy+Saline values. 
low dose radiation, are unsuccessful in treating GI toxicity induced by high-dose radiation exposures, or are ineffective as a post-exposure treatment for the thousands of potential exposed individuals. ${ }^{12,13}$

TP508 (Chrysalin) is an investigational peptide drug that was developed for use in stimulating repair of dermal and musculoskeletal tissues. ${ }^{14}$ TP508 is a 23 -amino acid peptide representing amino acids 508-530 of human prothrombin that was identified as the high-affinity binding domain of thrombin responsible for interaction with a subset of thrombin receptors on the surface of fibroblasts thought to initiate tissue repair. ${ }^{15,16}$ Specificity of TP508 has been demonstrated in both in vitro and in vivo experiments by altering the sequence and/or using scrambled peptides. ${ }^{17-20}$ TP508 was shown to initiate tissue repair and regeneration by reversing endothelial dysfunction, ${ }^{21}$ stimulating revascularization, ${ }^{22-24}$ attenuating inflammation, ${ }^{25}$ and reducing apoptosis. ${ }^{26}$ In human clinical trials, TP508 was shown to significantly increase healing of diabetic foot ulcers ${ }^{14,24,27}$ and distal radius fractures with no drug-related adverse events. ${ }^{14,24}$ Animal studies also showed that TP508 treatment regenerated bone in critical-size defects where new bone formation would not occur without intervention. ${ }^{28}$ Recently, this 23 -amino acid regenerative peptide has been shown to target stem/progenitor cells isolated from tissues and stimulate their proliferation. ${ }^{29}$ Thus, many of the tissue repair and regeneration effects of TP508 may be mediated by the activation of progenitor/stem cells within tissues.

It is well established that high-dose radiation exposure disrupts the normal homeostasis of crypts in the small intestine and colon. ${ }^{30}$ Certain growth factors and cytokines have been reported to have protective effects against radiationinduced damage to the intestinal epithelium. ${ }^{31}$ These factors are known to stimulate the proliferation of stem cells within the intestinal crypts. ${ }^{32,33}$ Given that TP508 stimulates stem cell proliferation $^{29}$ and regeneration of tissues, we hypothesized that TP508 may protect intestinal crypts or accelerate their regeneration by the upregulation of stem/progenitor cells to mitigate lethal effects of radiation exposure.

In this study, we show that TP508 effectively protects the intestinal mucosa from radiation-induced damage by increasing crypt stem cell proliferation, rescuing the stemness potential of the crypt cells, and preventing crypt disintegration post radiation exposure by maintaining E-cadherin adherens junctions. These protective effects of TP508 are seen in intestinal crypts (Supplementary Figures 1 and 2) and in colonic crypts (Figures 1, 2, 3 and 4) following 9 Gy (LD $\left.\mathrm{LD}_{100 / 15}\right)$ exposures. Importantly, mice treated with TP508 $24 \mathrm{~h}$ post $9 \mathrm{~Gy}$ exposure show a significant delay in the onset of mortality and a significant increase in survival. Therefore, TP508 may be an effective postexposure medicinal countermeasure for mitigating radiationinduced GI damage and mortality following a nuclear incident.

\section{MATERIALS AND METHODS}

\section{Reagents Used}

Antibodies used in this study include: anti-DCLK1, antiPCNA, and anti-GPCR GPR49 (Lgr5) (Abcam, Cambridge, MA, USA); anti-E-cadherin (Cell Signaling, Boston, MA); anti-active caspase-3 (Millipore, Temecula, CA, USA) and anti- $\beta$-actin (total) (Sigma, St Louis, MO, USA). Alexa Fluor594 and Alexa Fluor-488 coupled secondary IgG were purchased from Invitrogen (Carlsbad, CA, USA). DAPI (4',6-Diamidino-2-Phenylindole, Dihydrochloride) was purchased from Life Technologies (Grand Island, NY, USA). Saline (0.9\% Sodium Chloride Injection, USP) was purchased from Hospira (Lake Forest, IL, USA). Thrombin peptide TP508, a 23-amino acid peptide AGYKPDEGKRGDACEGD SGGPFV, also known as rusalatide acetate or Chrysalin, was synthesized and purified (GMP manufactured $>96 \%$ purity) by American Peptide Company (Sunnyvale, CA, USA) and provided by Chrysalis BioTherapeutics (Galveston, TX, USA).

a

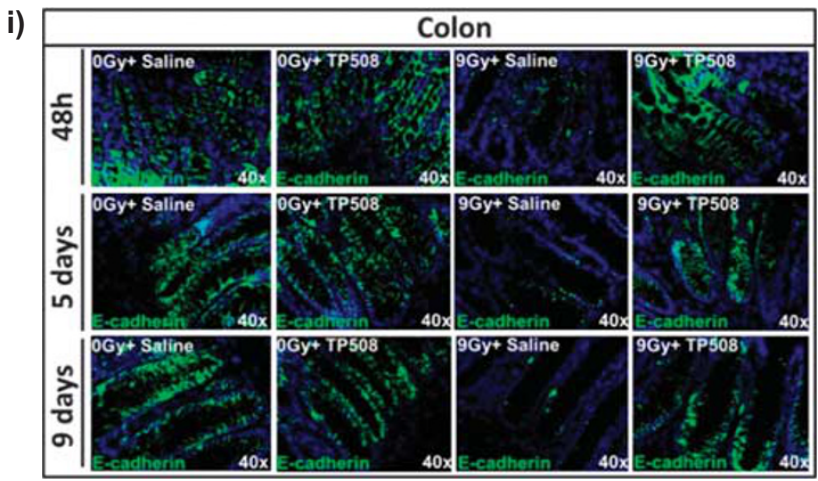

ii)

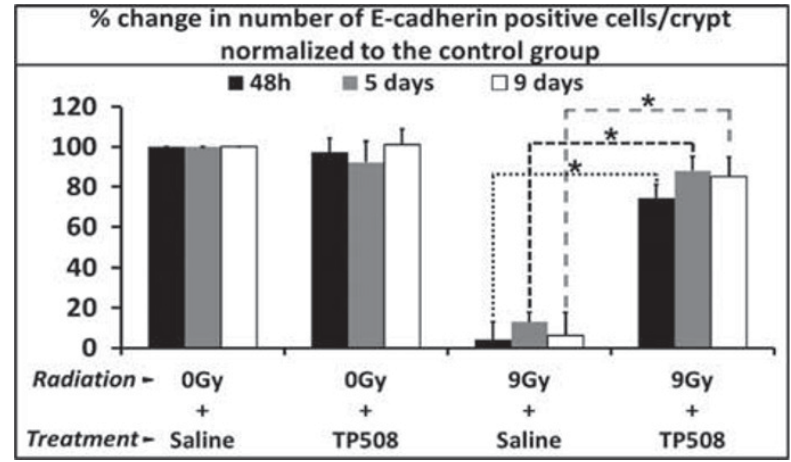

Figure 2 TP508 increases the expression of adherens junction E-cadherin and decreases apoptosis in gastrointestinal crypts post radiation exposure. (ai) Representative immunofluorescent images of colonic crypt sections harvested $48 \mathrm{~h}, 5$ days and 9 days post-RT and stained for E-cadherin. (aii) Bar graphs illustrating the \% change in the number of E-cadherin positive cells per crypt normalized to the control group (0 Gy + Saline). (bi) Immunofluorescent staining of colonic crypts sections harvested at $48 \mathrm{~h}, 5$ days and 9 days post-RT from mice treated with the indicated treatments for apoptotic marker activated-caspase-3. (bii) Bar graphs showing the percent change in the number of activated caspase-3 positive cells per crypt normalized to the control (0 Gy+Saline) group, isolated $48 \mathrm{~h}, 5$ days and 9 days post-RT, respectively. Data $=$ mean \pm s.e.m. from 6 mice/group/3 experiments. ${ }^{*} P<0.05$ vs $9 \mathrm{~Gy}+$ Saline values. 
b

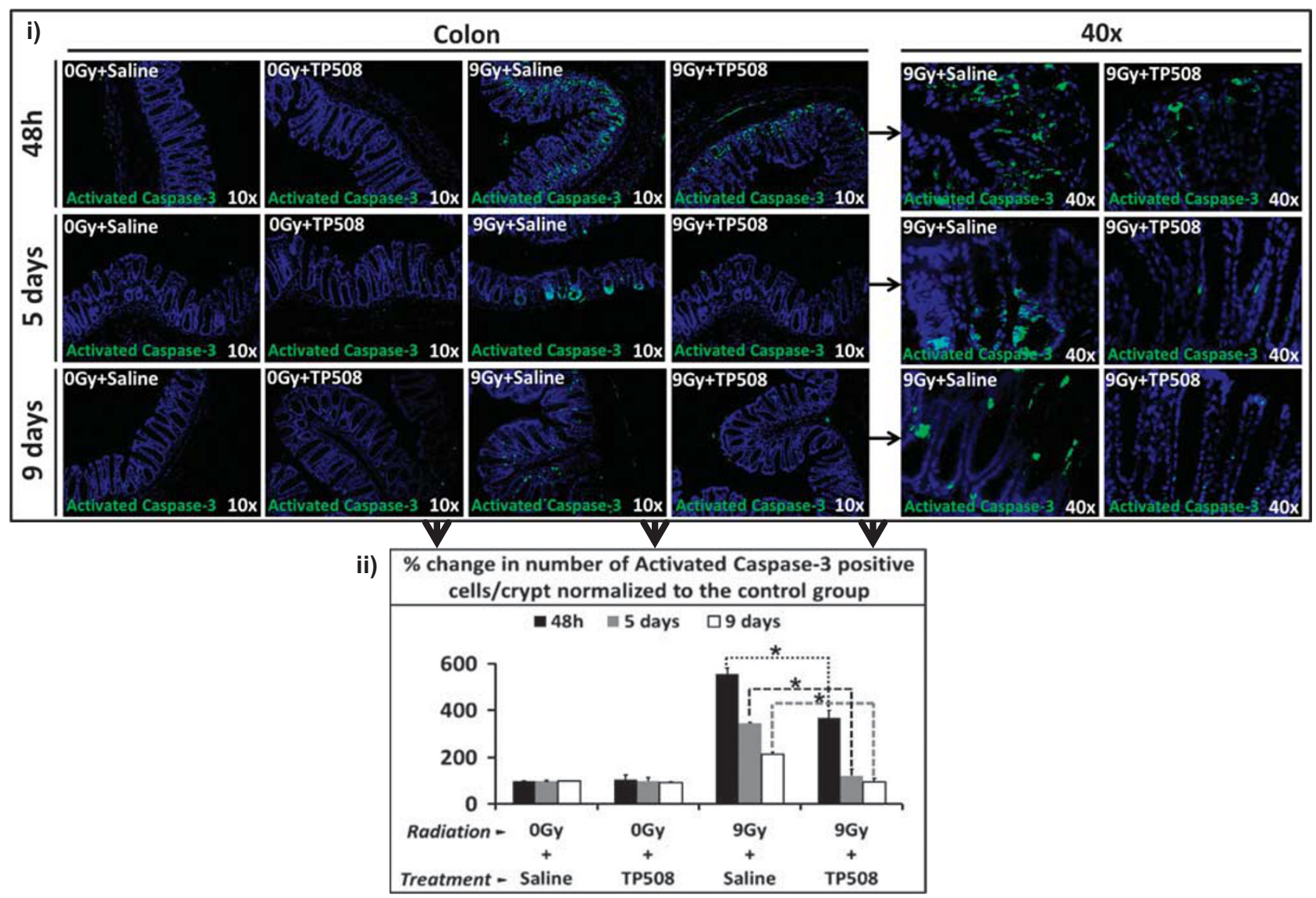

Figure 2 Continued.

\section{Irradiation and Treatment of Mice}

ICR (CD-1) outbred male mice were purchased from Harlan Laboratories (Houston, TX, USA). CD-1 outbred mice, which reflect natural heterogeneity in their radiosensitivity, were selected for these studies over inbred strains, which are known to be radiosensitive or radioresistant $\left(\mathrm{LD}_{50 / 30}\right.$ from 6.5 to $9.5 \mathrm{~Gy}$ ), based on specific genetic differences that affect their response to radiation-induced GI damage. ${ }^{34-36} \mathrm{LD}_{50 / 30}$ for ICR mice in our experiments is $\sim 8.5 \mathrm{~Gy}$, which falls midway within the reported range for various inbred species. Mice tested negative for viruses, bacteria, mycoplasma, or fungi and were considered Murine Pathogen-Free. Mice were allowed to acclimate for at least 7 days in the Animal Research Center at UTMB and were 12-13-weeks old upon the start of experiments. Mice were irradiated at approximately the same time $(10: 00 \mathrm{AM} \pm 1 \mathrm{~h})$ each day to minimize changes in circadian rhythms. Prior to irradiation, mice were anesthetized using isofluorane as per IACUC protocol and individually placed into a pie cage (10 mice/cage). The pie cage was then set inside a ${ }^{137} \mathrm{Cs}$ irradiator chamber (JL Shepherd and Associates, San Fernando, CA, USA) on a turntable to allow for uniform exposure. The mice were exposed to $9 \mathrm{~Gy}$ whole body radiation at a rate of $458 \mathrm{cGy} / \mathrm{min}$. To ensure accurate radiation dose exposure, a nanoDot OSLD dosimeter (LANDAUER, Glenwood, IL, USA) was simultaneously placed at the center of each pie, and dosimetry analysis for each experiment was performed and recorded. Twenty-four hours post radiation exposure, mice were injected intraperitoneally with a single dose of either saline alone or saline containing TP508 $(500 \mu \mathrm{g}$ or $12.5 \mathrm{mg} / \mathrm{kg})$.

\section{Isolation and Processing of Colonic Crypts from Mice}

Intact colonic crypts were isolated from mice $48 \mathrm{~h}, 5$ days and 9 days post radiation exposure as per a previously published method. ${ }^{37,38}$ Individual crypts were imaged with an inverted microscope at $\times 10$ and $\times 40$ magnifications using a white light microscope (Nikon Eclipse TS100, Melville, NY, USA). Some crypts were also collected to be processed for western blot analysis.

\section{Western Blot Analysis of Intact Colonic Crypts}

Cellular extracts were prepared from intact colonic crypts harvested $48 \mathrm{~h}$ and 9 days post radiation exposure, as previously described. ${ }^{39,40}$ Samples were processed by electrophoresis and transferred to PVDF membranes. ${ }^{39,40}$ Blots were cut into horizontal strips containing either the target or 


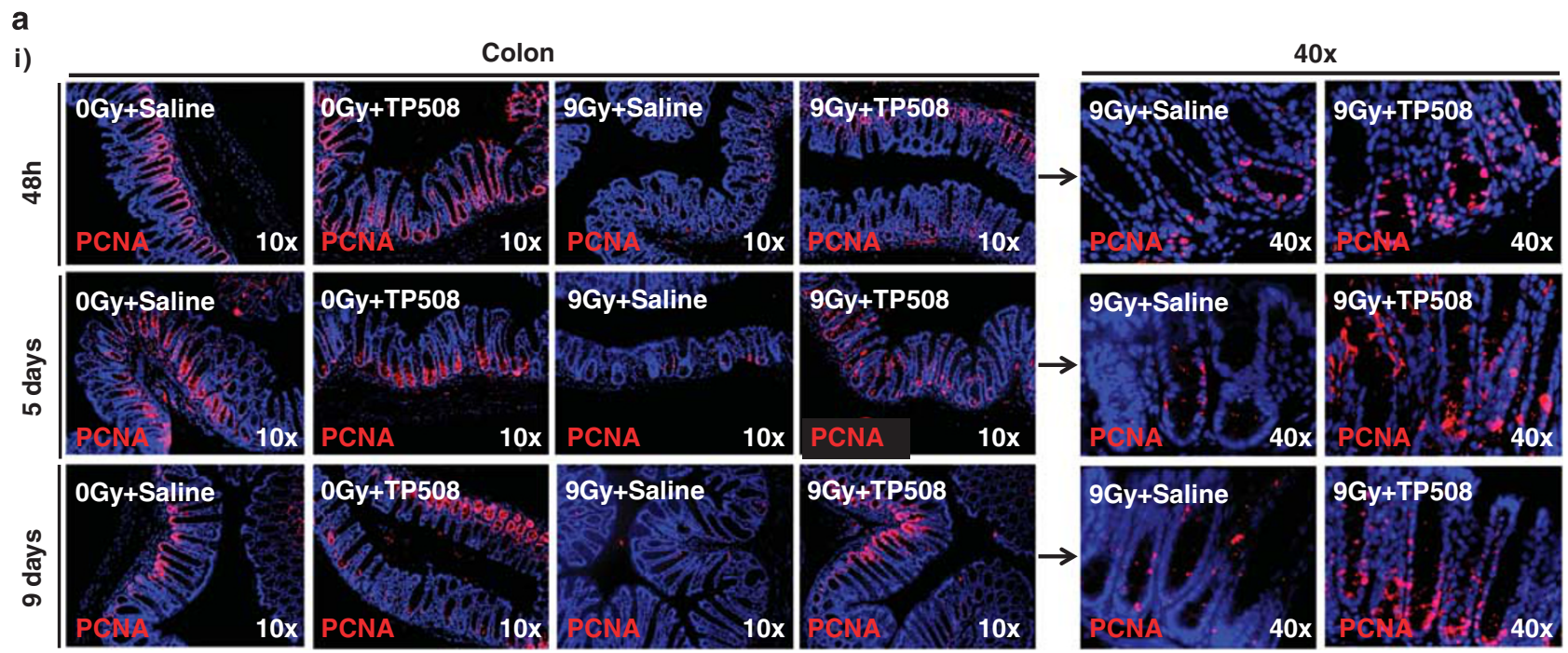

ii) change in number of PCNA positive cells/crypt
normalized to the control group

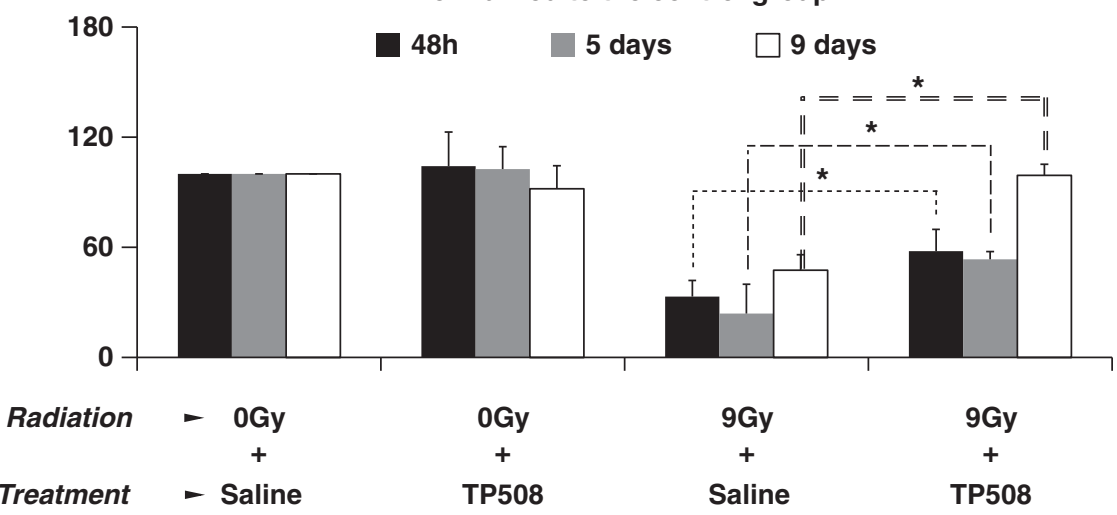

Figure 3 TP508 stimulates the proliferation of gastrointestinal crypt cells post radiation exposure. (ai) Representative images of colonic crypts sections harvested $48 \mathrm{~h}, 5$ days and 9 days post-RT from mice treated with the indicated treatments were stained for PCNA. (aii) Bar graphs showing the percent change in the number of PCNA positive cells per crypt normalized to the control ( 0 Gy+Saline) group, isolated $48 \mathrm{~h}, 5$ days and 9 days post-RT, respectively. Data $=$ mean \pm s.e.m. from 6 mice/group $/ 3$ experiments. ${ }^{*} P<0.05$ vs $9 \mathrm{~Gy}+$ Saline values. Ratio of control samples ( $0 \mathrm{~Gy}+$ Saline) were arbitrarily assigned $100 \%$ values; ratios of treated samples were expressed as a $\%$ of the control group. ${ }^{*} P<0.05$ vs control (9 Gy+Saline) values.

loading control protein $(\beta$-actin) and processed for detection of antigen-antibody complexes using a chemiluminescent reagent kit (GE Health Care, Piscataway, NJ, USA). ${ }^{39,40}$ Membrane strips containing target/loading control proteins were simultaneously exposed to autoradiographic films. $\beta$-actin was measured in corresponding samples containing equivalent protein.

\section{Immunofluorescence and Immunohistochemical Analysis of Small Intestinal and Colon Sections}

Small intestinal and colon tissues were fixed in formalin and processed using the UTMB's histology core for paraffin embedding and sectioning, followed by hemotoxylin and eosin (H\&E), and immunofluorescent (IF) staining, as previously described. ${ }^{41}$ On the basis of the H\&E staining of small intestine and colon tissue sections, crypt lengths were measured using a preset scale available on the Nikon NIS element software. Small intestinal and colon tissue paraffin sections were also stained by immunofluorescence using antiDCLK1 (1:200), anti-PCNA (1:300), anti-activated caspase-3 (1:100), and anti-E-cadherin (1:200). Images were acquired using Zeiss Axioplan epifluorescent microscope and analyzed using METAMORPH, v6.0 software (Molecular Devices).

\section{Survival Analysis of Mice}

Irradiated mice were monitored twice a day for the duration of thirty total days. Mice were killed based on a pain assessment scoring system consistent with our IACUC-approved 
a

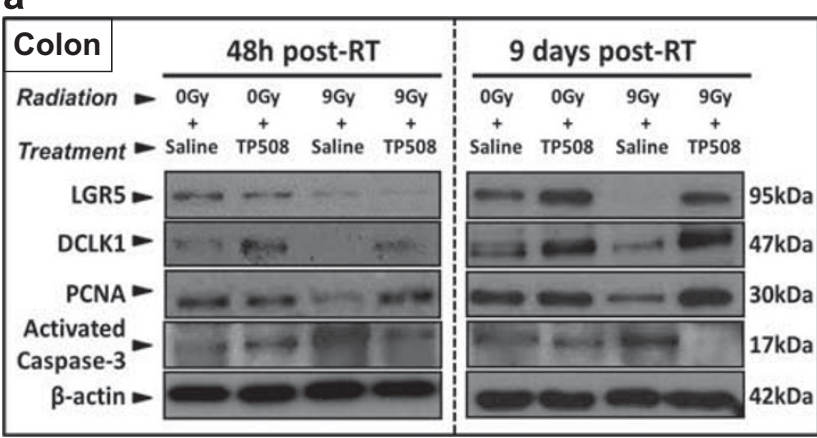

b
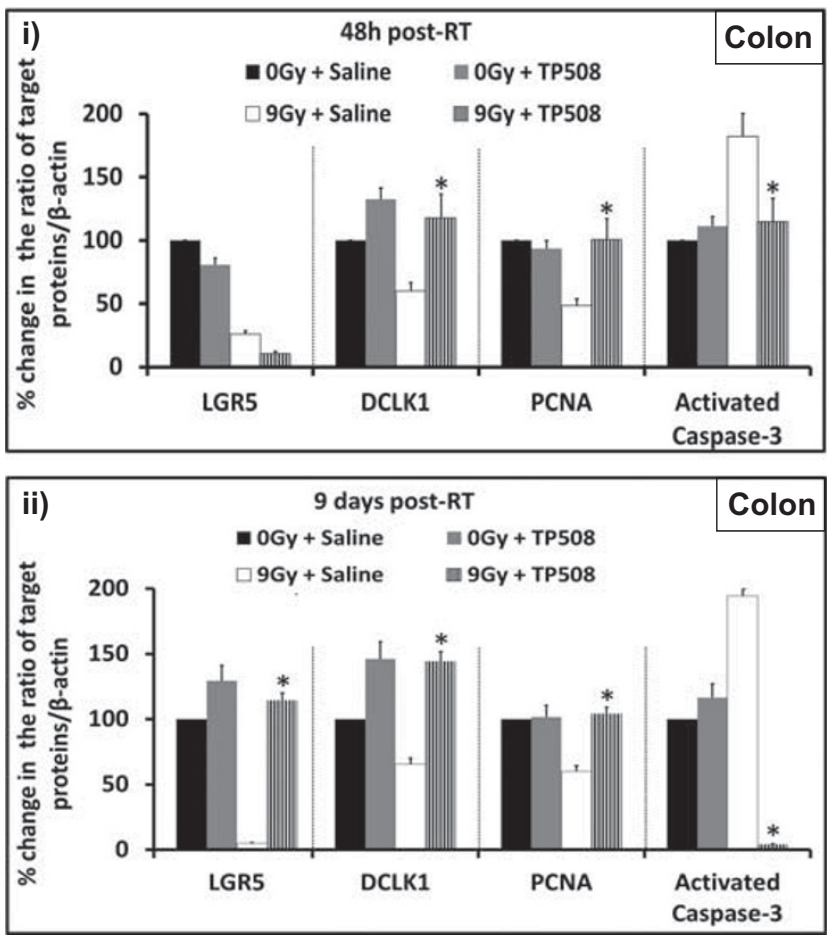

Figure 4 TP508 increases the stemness and proliferative potential of intact colonic crypts post radiation exposure while decreasing apoptosis (a) Western blot (WB) analysis demonstrating the expression of the indicated markers in Saline- vs TP508-treated groups at $48 \mathrm{~h}$ and 9 days post-RT. (bi, ii) Mean \pm s.e.m. of WB data from 4 mice/group $/ 3$ experiments, presented as $\%$ change in ratio of target protein $/ \beta$-actin from samples collected $48 \mathrm{~h}$ (i) and 9 days (ii) post-RT. Ratio of control samples ( $0 \mathrm{~Gy}+$ Saline) were arbitrarily assigned $100 \%$ values; ratios of treated samples were expressed as a $\%$ of control. ${ }^{*} P<0.05$ vs control (9 Gy+Saline) values.

protocol and/or at the veterinarian's discretion. For the purpose of our study, killing of a mouse equated to the occurrence of an event and therefore assigned a number of 1 , whereas all surviving mice by the end of the study were assigned the number 0 , indicative of no occurrence of an event. The data were analyzed using Kaplan-Meier Survival curves (GraphPad Prism Software). P-values were calculated using both the Gehan-Breslow-Wilcoxon test and the Logrank (Mantel-Cox) test as a secondary test to confirm our results. $P$-values on the graphs presented are that of the Gehan-Breslow-Wilcoxon test. Statistical significance was determined based on $P$-values of less than 0.05 .

\section{Statistical Analysis of Quantitative Data}

Quantitative analysis of data is presented as mean \pm s.e.m. of values obtained from 6 mice/group $/ 3$ experiments. All quantitative data were normalized to the non-irradiated control group ( $0 \mathrm{~Gy}+\mathrm{Saline})$. It is important to note that in this study, the student $T$-test was carried out using GraphPad Prism software (La Jolla, CA) to test for significant statistical differences only between the two irradiated groups ( $9 \mathrm{~Gy}$ +Saline vs 9 Gy+TP508). $P$-values were considered statistically significant if less than 0.05 .

\section{RESULTS}

\section{A Single Injection of TP508 Delays Crypt Dissociation and Accelerates Regeneration of New Crypts Post Radiation Treatment (RT)}

ICR (CD-1) mice (6 mice/group) were exposed to 9 Gy radiation, and treated with either saline or TP508 $24 \mathrm{~h}$ post exposure. Intact colonic crypts were harvested from the mice at $48 \mathrm{~h}, 5$ days and 9 days post-RT and imaged (Figure 1a). TP508 had no effect on crypts harvested from non-irradiated mice (left two panels in Figure 1a). In irradiated mice, colonic crypts were completely dissociated as a result of $9 \mathrm{~Gy}$ exposure in the saline-treated group, as early as $48 \mathrm{~h}$ post-RT. In contrast, TP508 treatment significantly prevented the dissociation of colonic crypts as depicted by the presence of both intact and partially intact crypts (top row). By day 5 post-RT (middle row), crypts began to regenerate in the TP508-treated group compared with the saline-treated group and appeared fully regenerated by day 9 post-RT (bottom row). Results suggest that TP508 may be either protecting crypts from breaking down or accelerating their regeneration. It is also important to note that these effects were initiated as early as $24 \mathrm{~h}$ post injection of TP508 and persisted up to 9 days post-RT. Colon tissue sections were also harvested and stained by H\&E staining. Representative H\&E images of colonic crypt sections, from mice in the indicated treatment groups, are shown in Figure 1bi. As shown, TP508-treated animals had increased colonic crypt length compared with the saline-treated animals at $48 \mathrm{~h}, 5$ days and 9 days post-RT. The percent change in crypt lengths was analyzed based on the $\mathrm{H} \& \mathrm{E}$ images and the data were normalized to the control (0 Gy+saline) group and presented as bar graphs in Figure 1bii. At $48 \mathrm{~h}$ post-RT, a $25 \%$ increase in crypt lengths was observed in the TP508- $v s$ saline-treated groups. At days 5 and 9 post$\mathrm{RT}$, on an average, a difference of $\sim 31 \%$ and $\sim 52 \%$ was observed, respectively. It is important to note that by day 9 post-RT, TP508 not only significantly increased crypt length compared with the saline-treated group, but actually restored the crypt length to that of healthy crypts in control mice, which received no radiation. Thus, whereas crypt integrity and length continued to decline with time in saline-treated 
animals, in TP508-treated animals, crypts were restored with time, suggesting that TP508 not only prevents early disintegration of crypts, but also stimulates their regeneration.

Shrinkage of small intestinal and colonic crypts, post-RT, has been reported to be associated with cellular death and loss of proliferation in the stem cell niche. ${ }^{42,43}$ Small intestinal crypts are reportedly more sensitive to radiation than colonic crypts. ${ }^{44}$ Therefore, we examined intestinal crypts to determine whether they were also protected/restored with postradiation TP508 treatment. As shown in Supplementary Figure 1ai-ii, TP508 treatment had similar effects in the small intestine as in the colon.

Breakdown of intestinal and colonic crypts is also thought to be due to weakened cell-cell adhesions. As cadherins have been shown to regulate cellular proliferation, apoptosis, and maintenance of crypt integrity, ${ }^{43,45}$ and TP508 appears to rescue crypt architecture, we next examined the effects of TP508 on the expression of E-cadherin, which is required for maintaining adherens junctions in GI crypts, and the amount of apoptosis in GI crypts.

\section{TP508 Increases the Expression of Adherens Junction Protein E-Cadherin and Decreases Apoptosis in GI Crypts Post Radiation Exposure}

Colon tissue sections harvested $48 \mathrm{~h}, 5$ days and 9 days postRT from mice were analyzed by IF for the expression of E-cadherin (Figure 2ai-ii). Results show that TP508 significantly increased the relative expression levels of E-cadherin as early as $48 \mathrm{~h}$ post-RT compared with that in the saline-treated group (Figure 2ai). The percent change in the number of E-cadherin-positive cells per colonic crypt is presented as a bar graph in Figure 2aii. As shown, RT in saline-treated animals resulted in $\sim 90 \%$ reduction in E-cadherin staining intensity; however, TP508 treatment attenuated the effects of radiation on relative levels of E-cadherin. At $48 \mathrm{~h}, 5$ days and 9 days post-RT, TP508 significantly increased the relative expression levels of E-cadherin by $>60 \%$, compared with the saline-treated group (Figure 2aii). IF analysis showed that TP508 also increased expression levels of E-cadherin in small intestine crypts similar to the increased expression observed in the colon (data not shown). These findings suggest that TP508 effects on adherens junction proteins may prevent early disintegration of intestinal crypts as observed in Figure 1bi.

Intestinal crypt tissue sections were also analyzed by IF staining for the expression of the apoptotic marker, activated caspase-3 in both the small intestine (Supplementary Figure 1B) and colon (Figure 2bi-ii). In crypts of non-irradiated mice, the expression of activated caspase- 3 was largely absent (left two panels), as would be expected in healthy crypts. However, at $48 \mathrm{~h}$ post-RT, the expression of activated caspase-3 was significantly increased in crypts harvested from saline-treated mice, but not in crypts from TP508-treated mice (Figure 2bi-ii). Caspase-3 was still activated at day 9 post-RT in the saline-treated group, but not in the
TP508-treated group (Figure 2bi-ii). The percent change in the number of activated caspase-3-positive cells per colonic crypt is presented as a bar graph in Figure 2bii. As shown, RT in saline-treated animals resulted in a five- to six-fold increase in apoptosis compared with the non-irradiated control mice. However, TP508 treatment decreased cellular death by 35\% at $48 \mathrm{~h}$ post-RT and by $\sim 95 \%$ at days 5 and 9 post-RT (Figure 2bii). These results indicate that, TP508 protection of intestinal crypts involves both increased expression of the adhesion molecule E-cadherin and a decrease in crypt cell apoptosis. On the basis of these results, it seemed likely that TP508 may also stimulate cell proliferation and activate progenitor/stem cells within the crypts to further enhance crypt regeneration.

\section{TP508 Increases Proliferation of GI Crypt Cells Post Radiation Exposure}

Small intestinal and colon tissue sections harvested $48 \mathrm{~h}$, 5 days and 9 days post-RT from mice treated with the indicated treatments were analyzed by IF for the cell proliferation marker PCNA. Results show that TP508 increased crypt cell proliferation as early as $48 \mathrm{~h}$ post-RT compared with the saline-treated group in both small (Supplementary Figure 1C) and large intestine (Figure 3ai-ii) and continued to do so up to 9 days post-RT. The percent change in the number of PCNA-positive cells per colonic crypt is presented as a bar graph in Figure 3aii. By day 9, proliferation of colonic crypt cells in the TP508-treated group was almost restored to that of non-irradiated crypt cells. These results demonstrate that TP508 is activating crypt cell proliferation by $48 \mathrm{~h}$ post-RT to prevent crypt dissociation, while also accelerating crypt regeneration by day 5 post-RT to promote formation of new crypts, as seen in Figure 1a.

\section{TP508 Increases the Stemness Potential of Intact Colonic Crypt Cells Post Radiation Exposure}

Given that stem cells are known to be responsible for maintaining and regulating the normal homeostasis of intestinal and colonic crypts, ${ }^{46}$ we next examined the effects of TP508 on the stemness potential of crypt cells post-RT. Using a method developed to specifically isolate crypts from colon (as described in the methods section), intact colonic crypts were isolated from mice treated with $\mathrm{RT} \pm \mathrm{TP} 508$ and processed for western blot analysis for the indicated markers. Representative data from three experiments are presented in Figure 4a. Data from blots are presented as a percent change in the ratio of relative levels of target proteins/ $\beta$-actin from samples collected at $48 \mathrm{~h}$ (Figure $4 \mathrm{bi}$ ) and 9 days (Figure $4 \mathrm{bii}$ ) post-RT. At $48 \mathrm{~h}$ post-RT, the expression of LGR5 was decreased, irrespective of TP508 treatment. However, at 9 days post-RT, the expression of LGR5 significantly increased by $>95 \%$ in the TP508-treated group compared with the control saline-treated group. Additionally, relative expression levels of DCLK1 was increased by $>50 \%$ at $48 \mathrm{~h}$ post-RT and by $>60 \%$ by day 9 post-RT in response to TP508. Western 
blot analysis also confirmed that the expression of PCNA was increased by $>50 \%$ in response to TP508 treatment post-RT while apoptosis (activated capase-3) was decreased by $>50$ $80 \%$, as presented in Figure 2 bi-ii and 3ai-ii. Small intestinal and colon sections were also harvested at $48 \mathrm{~h}, 5$ days and 9 days post-RT and processed for IF staining for stem cell marker DCLK1 (Figure 5ai-ii; Supplementary Figure 2A). No significant changes were observed in the non-irradiated treatment groups in both the small and large intestine. However, the number of DCLK-positive cells in the intestinal crypts was significantly increased in the TP508 vs saline groups, post-RT (Figure 5ai-ii; Supplementary Figure 2A). The percent change in the number of DCLK1-positive cells per colonic crypt at $48 \mathrm{~h}, 5$ days and 9 days post-RT was normalized to the control group ( $0 \mathrm{~Gy}+$ Saline $)$ and is presented as a bar graph in Figure 5aii. Data illustrate a
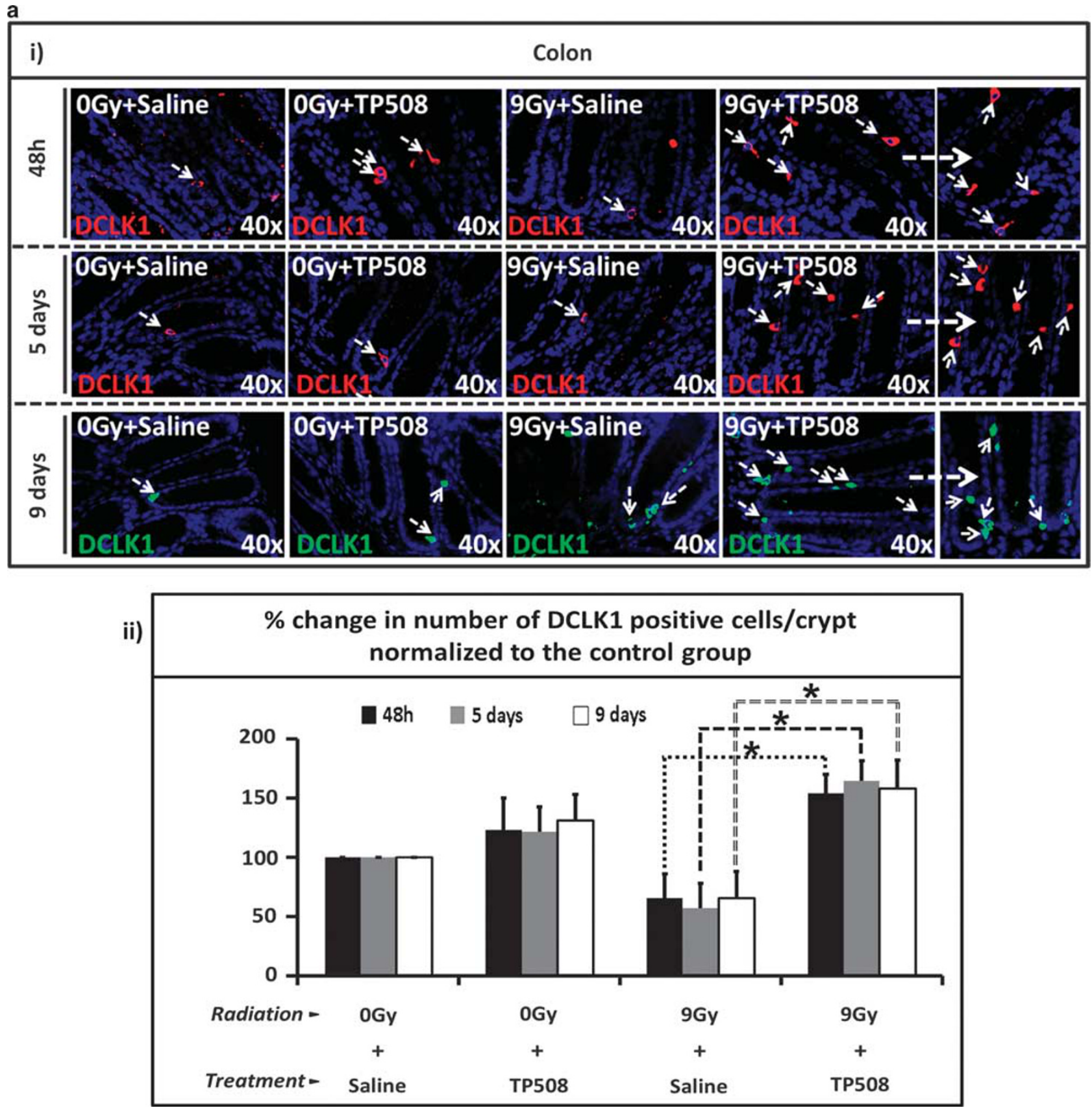

Figure 5 TP508 increases the number of DCLK1-positive cells in gastrointestinal crypts as early as $48 \mathrm{~h}$ post radiation exposure. (ai) Representative images of colonic crypt sections harvested $48 \mathrm{~h}, 5$ days and 9 days post-RT were stained by IF for DCLK1. White arrows depict positive staining for DCLK1. (aii) Bar graph illustrating the \% change in the number of DCLK1-positive cells per colonic crypt normalized to the control group (0 Gy+Saline), $48 \mathrm{~h}, 5$ days and 9 days post-RT. ${ }^{*} P<0.05$ vs corresponding control ( $9 \mathrm{~Gy}+$ Saline) values. 
significant increase in the number of DCLK1-positive cells $(>60 \%)$ at $48 \mathrm{~h}, 5$ days and 9 days post-RT in the TP508treated $v s$ saline groups.

\section{TP508 Significantly Delays Mortality and Increases Survival of Mice Post Radiation Exposure}

Exposure to high doses of total body irradiation (9-12 Gy) often results in death, regardless of intervention with advanced therapeutics or bone marrow transplants. ${ }^{3,4}$ This high mortality appears to be caused by radiation-induced damage to the intestinal and colonic mucosa leading to reduced fluid absorption, electrolyte imbalance, barrier function loss, bacterial translocation, systemic bacterial infection, sepsis, and organ failure. ${ }^{5-8}$ With the significant protective/restorative effects of TP508 on intestinal and colonic crypts following whole body irradiation, it seemed likely that TP508 may also increase animal survival with postirradiation treatment.

Mice were exposed to $9 \mathrm{~Gy}$ radiation and treated $24 \mathrm{~h}$ later with a single injection of either saline or TP508. TP508 treatment increased survival and delayed the onset of mortality in mice. On average, saline-treated mice died $\sim 12$ days post-RT, whereas TP508-treated mice died $\sim 17$ days post-RT (Figure 6a). Thus, TP508 delayed death by $\sim 4-$ 5 days in these mice. TP508 also significantly increased the survival of mice by $\sim 30.8 \%$, compared with the saline-treated group (Figure 6b). These findings demonstrate that the same TP508 treatment that mitigates effects of radiation on intestinal and colonic crypts, also significantly increases survival and delays mortality.

\section{DISCUSSION}

The increased probability of a nuclear incident in the world has led to a search for novel countermeasures capable of mitigating the potentially lethal effects of radiation on bone marrow, vital organs, and the GI tract. Recently, several agents, such as HB-EGF (Heparin-binding EGF-like growth factor), ${ }^{47}$ flavonolignan-silymarin, ${ }^{48} \mathrm{MG}$ (alpha2-macroglobulin), ${ }^{49}$ miso, ${ }^{50}$ and 17-DMAG (17-Dimethylaminoethylamino-17-demethoxygeldanamycin $)^{51}$ have been reported as novel putative radioprotective agents. However, these agents are only able to exert their protective effects when administered prior to radiation exposure and are ineffective post radiation. Similarly, mitigators such as Kruppel-like factor 4 (ref. 52) and DIM (3,3'-diindolylmethane) ${ }^{53}$ have also been reported to protect the GI tract from radiationinduced damage post exposure, but were either unable to initiate stem cell regeneration ${ }^{52}$ or required multiple injections for efficacy. ${ }^{53}$ In this study, we show that a single injection of TP508, administered $24 \mathrm{~h}$ post-RT, significantly increased survival and effectively protected the intestinal mucosa by delaying crypt dissociation, directly stimulating stem cell regeneration.

It is well known that breakdown of intestinal crypts postRT is associated with increased mortality and poor survival
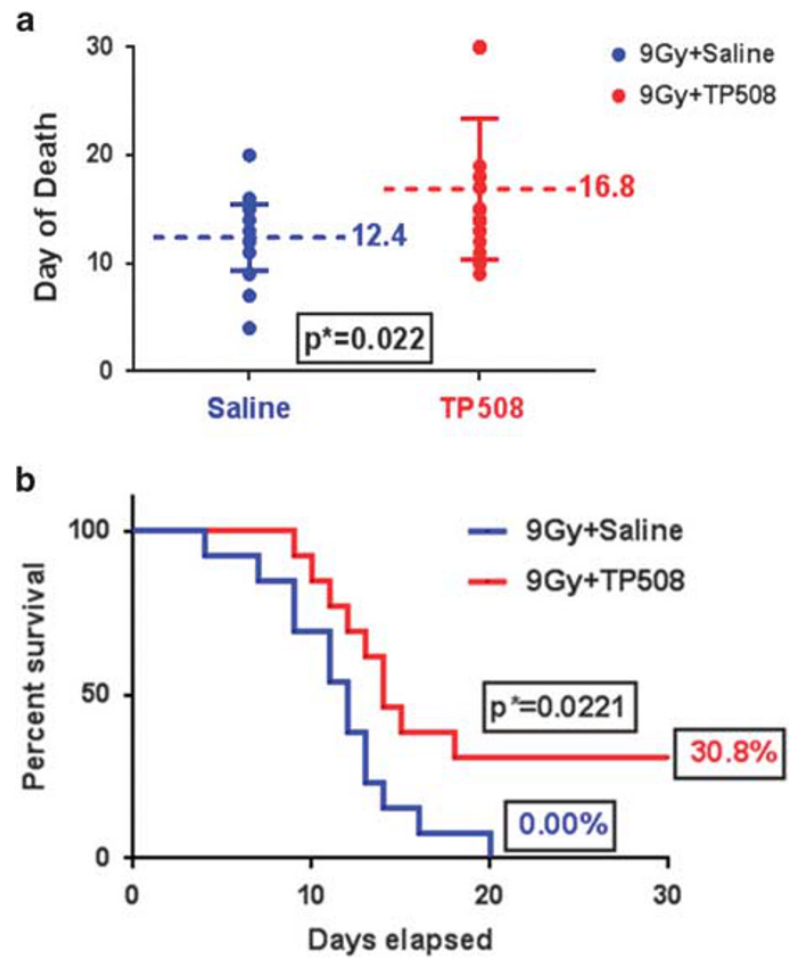

Figure 6 TP508 significantly delays mortality and increases survival post radiation exposure. (a) Scatter plot graph depicting the day of death of mice treated with the indicated treatments $(n=34)$. (b) Graph illustrating the percent survival of mice treated with the indicated treatments, monitored for a total of 30 days.

prognosis. ${ }^{54}$ This is due in part to the weakening of adherens junctions between crypt cells which increases permeability and results in intestinal leakage, bacterial translocation, sepsis, and ultimately death. ${ }^{55}$ In addition, radiation-induced damage to crypts has been associated with loss of E-cadherin expression in crypt cells. ${ }^{11}$ Interestingly, our results showed that TP508 delayed crypt dissociation in the colon (Figure 1a and $\mathrm{b}$ ) and in the small intestine (Supplementary Figure 1A) and increased the expression of E-cadherin post-RT (Figure 2ai-ii). These data suggest that TP508 may be preserving the integrity of GI crypts by strengthening the mucosal barrier, thus delaying the onset of acute GI toxicity. The severity of radiation exposure serves as an indicator of cellular death within the stem cell niche and is known to regulate the ability for crypts to regenerate. ${ }^{56}$ Furthermore, a decrease in crypt length post-RT has been reported to be associated with cellular death and loss of proliferation in the stem cell niche. ${ }^{42,43}$ Results showed that TP508 reversed radiation induced-damage by increasing crypt length (Figure 1a and b), increasing E-cadherin expression to reinforce adherens junctions, suppressing apoptosis (Figure 2bi-ii), and increasing cell proliferation within the crypts (Figures 3 and 4). Prevention of early breakdown of intestinal crypt appears to correlate with a significant delay in the onset of mortality (Figure 6a) and increase overall animal survival (Figure 6b). 
In addition to GI damage, exposure to high doses of total body irradiation has been shown to destroy bone marrow hematopoietic stem cells. ${ }^{57}$ Loss of hematopoietic stem cells leads to decreased white blood cells and promotes systemic infection and inflammatory responses that also cause GI damage, barrier dysfunction, and septic mortality. ${ }^{7,58,59}$ Our current experiments demonstrate that TP508 treatment increases survival of mice exposed to doses of radiation that are known to cause loss of hematopoietic cells and GI damage. Thus, TP508 effects on survival could be mediated by more than one mechanism. Preliminary data from our laboratory indicate that TP508 may activate hematopoietic stem cells in bone marrow of mice post-RT (not shown). Interestingly, hematopoietic syndrome-induced GI damage usually occurs $8-10$ days post exposure.$^{59}$ In our experiments, however, damage to colonic and intestinal crypts was observed within $48 \mathrm{~h}$ and 5 days of radiation exposure suggesting that in these mice, GI damage may be radiationinduced rather than a consequence of damage to hematopoietic cells. Thus, the increased survival of TP508-treated mice (Figure 6b) is likely due to TP508 protection and rescue of crypt epithelial stem/progenitor cells required for the regeneration and restoration of intestinal crypts.

Whereas at low doses of radiation, activation of cell proliferation post-RT helps delay damage sustained by the intestinal epithelium, at higher doses, the protection of progenitor/stem cells becomes imperative for crypt regeneration and survival. ${ }^{60}$ Crypts are composed of various heterogeneous subpopulation of cells with distinct proliferative and sensitivities to radiation damage. ${ }^{61,62}$ Both actively cycling and quiescent stem cells have an important role in the repair and regenerative process of the intestinal crypts post radiation damage. However, quiescent stem cells are more resistant to radiation damage compared with the susceptible proliferative stem cells. ${ }^{63}$ This is due in part to the lack of replication in quiescent stem cells, activation of rapid DNA repair mechanisms, and robust anti-apoptotic machinery, which are less prominent in proliferating cells. ${ }^{63,64}$ Therefore, quiescence seems to have a protective effect on the survival of crypt cells. ${ }^{62}$

It has been reported that the non-cycling quiescent cells, such as Lrig-positive ${ }^{65}$ and DCLK1-positive cells, ${ }^{66}$ and the slow cycling cells, such as Bmil-positive, ${ }^{67} m$ Tert-positive, ${ }^{68}$ and Hopx-positive ${ }^{69}$ cells, which are located at the +4 position, are more resistant to radiation damage compared with the actively cycling LGR5-positive cells. ${ }^{61}$ Although the proliferative LGR5-positive cells have been reported to be responsible for maintaining normal crypt homeostasis upon injury, it is the quiescent stem cell populations which are believed to become activated to give rise to new LGR5-positive cells and various types of intestinal cells. ${ }^{61}$ The dispensability of LGR5positive cells remains controversial. In more recent studies, LGR5-positive cells were reported to protect the GI tract from radiation-induced damage and deemed indispensable for the survival and regeneration of crypts post-RT. ${ }^{10}$ Equally, DCLK1 quiescent stem cells, also known to co-express LGR5, were shown to have a critical role in the restorative and restitution process of the intestinal epithelium..$^{70,71}$ Both LGR5 and DCLK1 expression in intestinal crypts were shown to be downregulated post-RT. ${ }^{72}$ Specifically, the expression of DCLK1-positive cells decreased $24-48 \mathrm{~h}$ post-RT and was undetectable by $3-4$ days post-RT. ${ }^{71}$

In our studies, TP508 significantly increased the expression of both LGR5 and DCLK1 stem cell markers in intestinal crypts (Figure 4) as well as the number of DCLK1-positive cells per crypt as early as $48 \mathrm{~h}$ post-RT (Figure 5, Supplementary Figure 2A). On the basis of our results, it appears that TP508 may promote the actively cycling stem cells to adopt a quiescent state to allow them to endure the stress of radiation damage and preserve their integrity (Figure $4 \mathrm{a}$ and $\mathrm{b} ; 48 \mathrm{~h}$ post-RT). However, by $5-9$ days post-RT, TP508 seems to be activating quiescent stem cells to give rise to new LGR5-positive cells (Figure 4a and b; 9 days post-RT). Regardless, our findings suggest that TP508 protects/rescues the crucial epithelial stem cells required for the renewal and survival of intestinal crypts post-RT.

Radiation exposure to the GI tract targets both intestinal stem cells and endothelial cells, which in turn results in the breakage of the mucosal barrier and lack of blood supply. ${ }^{73}$ Intestinal microvascular endothelial cells have been shown to help regulate crypt stem cells post injury. ${ }^{74}$ An increase in intestinal microvascular endothelial apoptosis resulted in extensive crypt damage and faster onset of GI syndrome. ${ }^{74}$ However, when endothelial apoptosis was inhibited, onset of GI syndrome was prevented. These studies suggest a strong correlation between the degree of endothelial apoptosis and the severity of crypt damage. ${ }^{74}$ In addition, rescuing endothelial cells from RT damage using bFGF resulted in increased crypt survival. Interestingly, the increase in crypt survival was not due to the stimulation of stem cells or crypt regeneration, but instead due to the halting of crypt shrinkage. ${ }^{74}$ In previous studies, TP508 was shown to stimulate endothelial cells to promote tissue revascularization, tissue repair, and protection. ${ }^{18,75}$ In our study, TP508 was shown to prevent crypt shrinkage (Figure 1a and b) and accelerate crypt regeneration (Figures 4 and 5) post-RT. Hence, it may be possible that TP508 prevents crypt shrinkage via its effects on endothelial cells while stimulating crypt regeneration via its direct effects on stem cells. However, further studies are required to better understand the molecular mechanisms by which TP508 exerts its protective effects on the GI tract.

In addition to endothelial activation response, radiation exposure also triggers and activates DNA repair mechanisms in injured crypt cells. ${ }^{76}$ Quiescent stem cells are able to more efficiently resist radiation damage and evade apoptosis due to the activation of a rapid non-homologous end joining DNA double strand break repair mechanism. ${ }^{77}$ In contrast, actively cycling cells use a more error-free homologous recombination repair pathway in response to damage. ${ }^{77,78}$ Our preliminary 
studies demonstrate that TP508 significantly decreases the expression of DNA double strand break marker, $\gamma \mathrm{H} 2 \mathrm{AX}$, in normal stem cells post-RT and increases the expression of DNA repair sensor ATM and effector Rad50 (data not shown). These results indicate that TP508 may protect stem cells from radiation-induced apoptosis by accelerating DNA repair mechanisms post radiation injury. Studies are currently underway to determine the mechanisms by which TP508 stimulates DNA repair and how this effect relates to TP508 mitigation of radiation-induced crypt damage.

Our overall goal is to develop effective medicinal countermeasures that can be delivered post exposure to help mitigate radiation-induced tissue damage and increase survival. Our results demonstrate that a single post-exposure injection of TP508 significantly increases animal survival, delays onset of mortality, and mitigates radiation-induced disintegration of colonic crypts by stimulating cell proliferation, increasing expression of adhesion molecules such as E-Cadherin, and activating crypt stem cells. Thus, TP508 may be an effective nuclear countermeasure to be used following an intentional or accidental nuclear incident to increase survival and provide high-exposure individuals additional time to be evacuated where they can receive additional life-saving medical treatment. TP508 can be easily distributed for onsite selfadministration.

Supplementary Information accompanies the paper on the Laboratory Investigation website (http://www.laboratoryinvestigation.org)

\section{ACKNOWLEDGMENTS}

We would like to acknowledge Daisy Ambriz, Yewen Wu, and Meng Zhong for their technical assistance. We would also like to thank Dr Bradford Loucas in the Department of Radiation Oncology at UTMB for his assistance with irradiating the mice. This work was supported by NIH grant R44AI086135 to DHC, CA097959 to PS, and The Jeane B. Kempner Scholarship to CK.

\section{DISCLOSURE/CONFLICT OF INTEREST}

Chrysalis BioTherapeutics has licensed worldwide exclusive rights to TP508 (Chrysalin) from The University of Texas Medical Branch. DHC has stock in, and receives compensation from, Chrysalis BioTherapeutics, Inc. Potential conflicts of interest are managed by the University of Texas Medical Branch Conflict of Interest and Commitment Committee.

1. Singh VK, Ducey EJ, Brown DS et al. A review of radiation countermeasure work ongoing at the Armed Forces Radiobiology Research Institute. Int J Radiat Biol 2012;88:296-310.

2. Moulder JE. Post-irradiation approaches to treatment of radiation injuries in the context of radiological terrorism and radiation accidents: a review. Int J Radiat Biol 2004;80:3-10.

3. Potten CS. Radiation, the ideal cytotoxic agent for studying the cell biology of tissues such as the small intestine. Radiat Res 2004;161: 123-136.

4. Dorr $\mathrm{H}$, Meineke V. Acute radiation syndrome caused by accidental radiation exposure - therapeutic principles. BMC Med 2011;9:126.

5. Gits J, Gerber GB. Electrolyte loss, the main cause of death from the gastrointestinal syndrome? Radiat Res 1973;55:18-28.

6. Dublineau I, Ksas B, Aigueperse J et al. In vivo alterations of fluid and electrolyte fluxes in rat colon by gamma irradiation. Dig Dis Sci 1998:43:652-662.
7. Naftalin R. Alterations in colonic barrier function caused by a low sodium diet or ionizing radiation. J Environ Pathol Toxicol Oncol 2004;23:79-97.

8. Booth C, Tudor G, Tudor J et al. Acute gastrointestinal syndrome in high-dose irradiated mice. Health Phys 2012;103:383-399.

9. Booth C, Potten CS. Gut instincts: thoughts on intestinal epithelial stem cells. J Clin Invest 2000;105:1493-1499.

10. Metcalfe C, Kljavin NM, Ybarra R et al. Lgr5+ stem cells are indispensable for radiation-induced intestinal regeneration. Cell Stem Cell 2014;14:149-159.

11. Thiagarajah JR, Gourmelon P, Griffiths NM et al. Radiation induced cytochrome $\mathrm{c}$ release causes loss of rat colonic fluid absorption by damage to crypts and pericryptal myofibroblasts. Gut 2000;47: 675-684.

12. Waselenko JK, MacVittie TJ, Blakely WF et al. Medical management of the acute radiation syndrome: recommendations of the Strategic National Stockpile Radiation Working Group. Ann Intern Med 2004;140: 1037-1051.

13. Taniguchi CM, Miao YR, Diep AN et al. PHD inhibition mitigates and protects against radiation-induced gastrointestinal toxicity via HIF2. Sci Transl Med 2014;6:236ra264.

14. Carney DH, Olszewska-Pazdrak B. Could rusalatide acetate be the future drug of choice for diabetic foot ulcers and fracture repair? Expert Opin Pharmacother 2008;9:2717-2726.

15. Glenn KC, Frost GH, Bergmann JS et al. Synthetic peptides bind to high-affinity thrombin receptors and modulate thrombin mitogenesis. Pept Res 1988;1:65-73.

16. Stiernberg J, Redin WR, Warner WS et al. The role of thrombin and thrombin receptor activating peptide (TRAP-508) in initiation of tissue repair. Thromb Haemost 1993;70:158-162.

17. Naldini A, Carraro F, Baldari CT et al. The thrombin peptide, TP508, enhances cytokine release and activates signaling events. Peptides 2004;25:1917-1926.

18. Tsopanoglou NE, Papaconstantinou ME, Flordellis CS et al. On the mode of action of thrombin-induced angiogenesis: thrombin peptide, TP508, mediates effects in endothelial cells via alphavbeta3 integrin. Thromb Haemost 2004;92:846-857.

19. Carney DH, Mann R, Redin WR et al. Enhancement of incisional wound healing and neovascularization in normal rats by thrombin and synthetic thrombin receptor-activating peptides. J Clin Invest 1992;89: 1469-1477.

20. Schwartz Z, Carney DH, Crowther RS et al. Thrombin peptide (TP508) treatment of rat growth plate cartilage cells promotes proliferation and retention of the chondrocytic phenotype while blocking terminal endochondral differentiation. J Cell Physiol 2005;202:336-343.

21. Fossum TW, Olszewska-Pazdrak B, Mertens MM et al. TP508 (Chrysalin) reverses endothelial dysfunction and increases perfusion and myocardial function in hearts with chronic ischemia. J Cardiovasc Pharmacol Ther 2008;13:214-225.

22. Norfleet AM, Bergmann JS, Carney DH. Thrombin peptide, TP508, stimulates angiogenic responses in animal models of dermal wound healing, in chick chorioallantoic membranes, and in cultured human aortic and microvascular endothelial cells. Gen Pharmacol 2000;35: 249-254.

23. Wang H, Li X, Tomin E et al. Thrombin peptide (TP508) promotes fracture repair by up-regulating inflammatory mediators, early growth factors, and increasing angiogenesis. J Orthop Res 2005;23:671-679.

24. Ryaby JT, Sheller MR, Levine BP et al. Thrombin Peptide TP508 Stimulates Cellular Events Leading to Angiogenesis, Revascularization, and Repair of Dermal and Musculoskeletal Tissues. J Bone Joint Surg Am 2006;88(Suppl 3):132-139.

25. Stiernberg J, Norfleet AM, Redin WR et al. Acceleration of full-thickness wound healing in normal rats by the synthetic thrombin peptide, TP508. Wound Repair Regen 2000;8:204-215.

26. Zhong M, Carney DH, Ryaby JT et al. Inhibition of phosphate-induced apoptosis in resting zone chondrocytes by thrombin peptide 508. Cells Tissues Organs 2009;189:56-59.

27. Fife C, Mader JT, Stone J et al. Thrombin peptide Chrysalin stimulates healing of diabetic foot ulcers in a placebo-controlled phase $\mathrm{I} / \mathrm{Il}$ study. Wound Repair Regen 2007;15:23-34.

28. Sheller MR, Crowther RS, Kinney JH et al. Repair of rabbit segmental defects with the thrombin peptide, TP508. J Orthop Res 2004;22: 1094-1099. 
29. Freyberg S, Song YH, Muehlberg $\mathrm{F}$ et al. Thrombin peptide (TP508) promotes adipose tissue-derived stem cell proliferation via PI3 kinase/ Akt pathway. J Vasc Res 2009;46:98-102.

30. Harfouche G, Martin MT. Response of normal stem cells to ionizing radiation: a balance between homeostasis and genomic stability. Mutat Res 2010;704:167-174.

31. Hendry JH, Booth C, Potten CS. Endothelial cells and radiation gastrointestinal syndrome. Science 2001;294:1411.

32. Withers HR, Elkind MM. Radiosensitivity and fractionation response of crypt cells of mouse jejunum. Radiation research 1969;38:598-613.

33. Cairnie $A B$, Millen BH. Fission of crypts in the small intestine of the irradiated mouse. Cell Tissue Kinet 1975;8:189-196.

34. Chia R, Achilli F, Festing MF et al. The origins and uses of mouse outbred stocks. Nat Genet 2005;37:1181-1186.

35. Tajima G, Delisle AJ, Hoang $\mathrm{K}$ et al. Immune system phenotyping of radiation and radiation combined injury in outbred mice. Radiat Res 2013;179:101-112.

36. Williams JP, Brown SL, Georges GE et al. Animal models for medical countermeasures to radiation exposure. Radiat Res 2010;173:557-578.

37. Wang $Y$, Xiang GS, Kourouma $F$ et al. Citrobacter rodentium-induced NF-kappaB activation in hyperproliferating colonic epithelia: role of p65 (Ser536) phosphorylation. Br J Pharmacol 2006;148:814-824.

38. Peleg $\mathrm{S}$, Sellin $\mathrm{JH}$, Wang $Y$ et al. Suppression of aberrant transient receptor potential cation channel, subfamily $\mathrm{V}$, member 6 expression in hyperproliferative colonic crypts by dietary calcium. Am J Physio Gastrointest Liver Physiol 2010;299:G593-G601.

39. Kantara C, O'Connell MR, Luthra G et al. Methods for detecting circulating cancer stem cells (CCSCs) as a novel approach for diagnosis of colon cancer relapse/metastasis. Lab Invest 2014

40. Kantara C, O'Connell M, Sarkar S et al. Curcumin promotes autophagic survival of a subset of colon cancer stem cells, which are ablated by DCLK1-siRNA. Cancer Res 2014;74:2487-2498.

41. Sarkar S, Kantara C, Ortiz I et al. Progastrin overexpression imparts tumorigenic/metastatic potential to embryonic epithelial cells: phenotypic differences between transformed and nontransformed stem cells. Int J Cancer 2012;131:E1088-E1099.

42. Martin K, Potten CS, Roberts SA et al. Altered stem cell regeneration in irradiated intestinal crypts of senescent mice. J Cell Sci 1998;111(Pt 16): 2297-2303.

43. Hermiston ML, Wong MH, Gordon Jl. Forced expression of E-cadherin in the mouse intestinal epithelium slows cell migration and provides evidence for nonautonomous regulation of cell fate in a self-renewing system. Genes Dev 1996;10:985-996.

44. Potten CS, Grant HK. The relationship between ionizing radiationinduced apoptosis and stem cells in the small and large intestine. Br J Cancer 1998;78:993-1003.

45. Escaffit $F$, Perreault N, Jean D et al. Repressed E-cadherin expression in the lower crypt of human small intestine: a cell marker of functional relevance. Exp Cell Res 2005;302:206-220.

46. Tan DW, Barker N. Intestinal stem cells and their defining niche. Curr Top Dev Biol 2014;107:77-107.

47. Matthews MA, Watkins D, Darbyshire A et al. Heparin-binding EGF-like growth factor (HB-EGF) protects the intestines from radiation therapyinduced intestinal injury. J Pediatr Surg 2013;48:1316-1322.

48. Adhikari M, Arora R. The flavonolignan-silymarin protects enzymatic hematological, and immune system against gamma-radiation-induced toxicity. Environ Toxicol; e-pub ahead of print 20 November 2014.

49. Mihailovic M, Dobric S, Poznanovic G et al. The acute-phase protein alpha2-macroglobulin plays an important role in radioprotection in the rat. Shock 2009;31:607-614.

50. Ohara $M$, Lu $H$, Shiraki $K$ et al. Radioprotective effects of miso (fermented soy bean paste) against radiation in B6C3F1 mice: increased small intestinal crypt survival, crypt lengths and prolongation of average time to death. Hiroshima J Med Sci 2001;50: $83-86$.

51. Lu X, Nurmemet D, Bolduc DL et al. Radioprotective effects of oral 17dimethylaminoethylamino-17-demethoxygeldanamycin in mice: bone marrow and small intestine. Cell Biosci 2013;3:36.

52. Talmasov D, Xinjun Z, Yu B et al. Kruppel-like factor 4 is a radioprotective factor for the intestine following gamma-radiationinduced gut injury in mice. Am J Physiol Gastrointest Liver Physiol 2014;308:G121-G138.
53. Fan S, Meng $\mathrm{Q}$, Xu J et al. DIM (3,3'-diindolylmethane) confers protection against ionizing radiation by a unique mechanism. Proc Natl Acad Sci USA 2013:110:18650-18655.

54. Carter SR, Zahs A, Palmer JL et al. Intestinal barrier disruption as a cause of mortality in combined radiation and burn injury. Shock 2013;40:281-289.

55. Somosy Z, Bognar G, Thuroczy G et al. Biological responses of tight junction to ionizing radiation and electromagnetic field expostion. Cell Mol Biol (Noisy-le-grand) 2002;48:571-575.

56. Inagaki-Ohara K, Takamura N, Yada $\mathrm{S}$ et al. Radiation-induced crypt intestinal epithelial cell apoptosis in vivo involves both caspase-3dependent and -independent pathways. Dig Dis Sci 2002;47:2823-2830.

57. Shao L, Luo Y, Zhou D. Hematopoietic stem cell injury induced by ionizing radiation. Antioxid Redox Signal 2014;20:1447-1462.

58. Shakhov AN, Singh VK, Bone F et al. Prevention and Mitigation of Acute Radiation Syndrome in Mice by Synthetic Lipopeptide Agonists of Toll-Like Receptor 2 (TLR2). PloS ONE 2012;7:e33044.

59. Koenig KL, Goans RE, Hatchett RJ et al. Medical treatment of radiological casualties: current concepts. Ann Emerg Med 2005;45: 643-652.

60. Son TG, Gong EJ, Bae MJ et al. Protective effect of genistein on radiation-induced intestinal injury in tumor bearing mice. BMC Complement Altern Med 2013;13:103

61. Shivdasani RA. Radiation redux: reserve intestinal stem cells miss the call to duty. Cell Stem Cell 2014;14:135-136.

62. Liu JC, Lerou PH, Lahav G. Stem cells: balancing resistance and sensitivity to DNA damage. Trends Cell Biol 2014;24:268-274.

63. Cheung TH, Rando TA. Molecular regulation of stem cell quiescence. Nat Rev Mol Cell Biol 2013;14:329-340.

64. Maugeri-Sacca M, Bartucci M, De Maria R. DNA damage repair pathways in cancer stem cells. Mol Cancer Ther 2012;11:1627-1636.

65. Jensen KB, Watt FM. Single-cell expression profiling of human epidermal stem and transit-amplifying cells: Lrig1 is a regulator of stem cell quiescence. Proc Natl Acad Sci USA 2006;103:11958-11963.

66. May R, Sureban SM, Hoang $\mathrm{N}$ et al. Doublecortin and CaM kinase-like-1 and leucine-rich-repeat-containing G-protein-coupled receptor mark quiescent and cycling intestinal stem cells, respectively. Stem Cells 2009;27:2571-2579.

67. Yan KS, Chia LA, Li X et al. The intestinal stem cell markers Bmi1 and Lgr5 identify two functionally distinct populations. Proc Natl Acad Sci USA 2012;109:466-471.

68. Montgomery RK, Carlone DL, Richmond CA et al. Mouse telomerase reverse transcriptase (mTert) expression marks slowly cycling intestinal stem cells. Proc Natl Acad Sci USA 2011;108:179-184.

69. Takeda N, Jain R, LeBoeuf MR et al. Interconversion between intestinal stem cell populations in distinct niches. Science 2011;334:1420-1424.

70. Itzkovitz S, Lyubimova A, Blat IC et al. Single-molecule transcript counting of stem-cell markers in the mouse intestine. Nat Cell Biol 2012;14:106-114.

71. May R, Qu D, Weygant $\mathrm{N}$ et al. Brief report: Dclk1 deletion in tuft cells results in impaired epithelial repair after radiation injury. Stem Cells 2014;32:822-827.

72. Cheasley D, Pereira L, Lightowler $\mathrm{S}$ et al. Myb controls intestinal stem cell genes and self-renewal. Stem Cells 2011;29:2042-2050.

73. Wang J, Boerma M, Fu Q et al. Significance of endothelial dysfunction in the pathogenesis of early and delayed radiation enteropathy. World J Gastroenterol 2007;13:3047-3055.

74. Maj JG, Paris F, Haimovitz-Friedman A et al. Microvascular function regulates intestinal crypt response to radiation. Cancer Res 2003;63: 4338-4341.

75. Olszewska-Pazdrak B, Hart-Vantassell A, Carney DH. Thrombin peptide TP508 stimulates rapid nitric oxide production in human endothelial cells. J Vasc Res 2010;47:203-213.

76. Denham JW, Hauer-Jensen M. The radiotherapeutic injury-a complex 'wound'. Radiother Oncol 2002;63:129-145.

77. Sancar A, Lindsey-Boltz LA, Unsal-Kacmaz $\mathrm{K}$ et al. Molecular mechanisms of mammalian DNA repair and the DNA damage checkpoints. Annu Rev Biochem 2004;73:39-85.

78. Weinstock DM, Richardson CA, Elliott B et al. Modeling oncogenic translocations: distinct roles for double-strand break repair pathways in translocation formation in mammalian cells. DNA Repair (Amst) 2006:5:1065-1074. 